\section{ON LITHECTASY,}

OR THE

EXTRACTION OF STONE FROM BY

\section{SLOW and PAINLESS DILATATION.}

To the Editor of The LANCET.

SIR,-I shall feel obliged by your permitting me, through the medium of your widely-circulated Journal, to lay before the profession some details respecting the recently-introduced operation of removing urinary calculus by slow and painless dilatation. As the subject has often engaged my thoughts, many ideas of a practical nature have occurred to me, which those who have determined upon performing the operation may find an advantage in being acquainted with; and some mistakes may thereby be obviated which, otherwise, by detracting from the excellence of the operation or its reputation, at the outset, might retard its general introduction into practice. It is my object, by showing how easily and safely this operation may be performed (provided its great principle be attended to, namely, the avoiding of every sort of violence), that it shall not be confined, as the operations of lithotomy and lithotrity are, to hospital surgeons, or those practised in capital operations, and who have thereby acquired the confidence and presence of mind fitting them to contend with unexpected difficulties in the midst of suffering and danger, but that it shall be within the reach of every intelligent surgeon who will take the pains to make himself familiar with the use of the necessary apparatus. I am, Sir, your obedient servant,

$$
\text { James Arnott, M.D. }
$$

\section{Brighton, July $20,1843$.}

The idea is very generally entertained that the operation for stone is not so fatal as heretofore, owing to the improvements of it in recent times, and particularly by continental surgeons. But the most recent statistical report of lithotomy and lithotrity, quoted in the last number but one of THE LANeET (page 511), from a French medical journal, and referring to the principal huspital of Europe, the Hôtel Dieu, of Paris, shows that of thirty cases in which these operations have been performed there during the last six years, twelve have died, or two in five; and of these a considerable number were children, in whom the operation is comparatively safe. Allowing that this is above the average rate of mortality, and estimating it at only half the amount, it is still frightfully great, and affords abundant reason for further investigation with the view of discovering a less fatal plan of treatment than any of those in use.*

The lateral operation of lithotomy has now been practised for about one hundred and fifty years. The Marian operation, or lithotomy by the apparatus major, which preceded it, and of which dilatation of the

* Dr. Willis, who is our best authority on the statistics of the operations for stone, states that the mortality, after forty years of age, is " certainly not less than one in four." Amongst the numerous summaries given in his work "On the Treatment of Stone" of the results of operations at public institu. tions and in private, the following statement, by M. Velpeau, merits particular notice, as well on account of the importance of the facts related as from the character of the distinguished reporter :-“ In a grand total of 1003 patients who have come under the hands of lithotritists, 616 only have been delivered of their calculi, and 387 have died, or have not been relieved." We learn from another statement by the same writer, that of 206 patients upon whom M. Civiale had performed lithotrity, 80 died (or nearly 2 in 5 die the same mortality as that reported above as having occurred at the Hotel Dieu), and eighteen retained the stone, who would probably eventually be lost. An erroneous impression is too apt to be made on the public mind respecting the mortality from lithotomy by the often-vaunted success of some fortunate operators; and he performs an essential service to humanity who, by accurate inquiries into the records of hospitals, removes this baneful delusion. The records of private operations, or those pub. lished by individuals of their own success, are far from being of equal weight with those of public institutions. That of Mr. Martineau, for instance, one of the most celebrated English lithotomists of late times, is declared by him to have included every case brought for operation, and it is affirmed " that no selection of patients was made;" whereas we are informed by a witness, during many years, of this surgeon's publie practice, and who is himself an eminent operator, that ${ }^{6}$ he carefully selected his patients." Highly dangerous as these operations are proved to be by such statistical details, there cannot be a doubt that if their remote results were ascertained as well those that are immediate, it would be found that many apparent recoveries were ouly alleviations of misery, and that death has followed the operation at a later period. Such an investigation would, $I$ apprehend, afford too much foundation for the opinion which M. Richerand has expressed, that " we cannot promise life, with final recovery, to above one half of all who are subjected to lithotomy." (Hist. des Progrès Recens de Chirurgie, 1825.) 
more important parts, instead of cutting, quence of lithotomy and lithotrity principally was the professed principle, had been in use during a similar or greater period.

The Marian operation fell into disrepute because the laceration produced by the instruments intended for dilatation was supposed to be much more dangerous and painful than the division of the same parts by the knife.

In the estimation of the dangers of the old operation and the advantages of the new, there was doubtless much exaggeration. Le Dran mentions that of sixteen operations by the apparatus major, which he performed before numerous witnesses at the Hôpital de la Charité, in Paris, in the years 1728 and 1729 , every one was perfectly successful, notwithstanding that in many of the cases the stones, were unusually large, weighing from six to eight ounces. The average mortality from cutting has been already mentioned.

The original lateral operation, in which there was extensive incision of the inner parts, has fallen into disuse, principally from the circumstance that such incision permits the ready infiltration of urine into the cellular membrane surrounding the neck of the bladder, which becomes the source of violent and often fatal inflammation.

The present most approved operation of lithotomy, although still called the lateral operation, approaches more nearly, in all essential particulars, the old proceeding by the apparatus major. The main distinction between the two methods does not consist in the number or form of instruments employed, but in the purpose they are calculated to accomplish. The great object is to make a sufficient opening into the bladder, and this may be done either by cutting or by quick dilatation. Whether the sudden distention and laceration are made by a steel dilator, by a blunt gorget or wedge, by the finger, or by the forceps singly or while grasping the stone, is really a very immaterial circnmstance. There is, indeed, a small incision made in the present operation, previously to the stretching, which determines the direc. tion of the laceration, just as a notch is made in a piece of cloth previously to tearing it; but so was there also, latterly, in the Marian operation, under the name of the "coup de muitre." By some operators this incision was not carried farther than the prostate gland (Bromfield cut the fore part of it), while others extended it along the whole of the prostatic urethra. The operatiun of lithotomy must, at any rate, be acknowledged to have retrograded to its state of transition between the old and new methods, and this has, perhaps, been wisely done; for it may be better that it should partake slightly of the evils of both than exclusively possess that of either in a great degree.

From what has the mortality in conseproceeded? From inflammation, caused either by violence in opening a passage for the stone; or by the infiltration of urine; or by rudely acting with instruments on the sensitive and irritable coats of the bladder.

The sudden stretching and laceration produced by the apparatus major, when it was the ambition of the surgeon, as we are told by Le Dran, thus to remove stone within the minute, and that produced in the present day by operators who only slightly cut the prostate, and are yet anxious to put a period to the patient's torture by tinishing the operation in the shortest possible time, are instances of violence. Large incision and the repeated operations of the lithotritist, are not less calculated to excite inflammation in the other ways mentioned.

Can stone be removed without violence, infiltration of urine, injury to the coats of the Ibladder, hæmorrhage, exhaustion from long-continued and severe pain, or other canses of death from the operations now and heretofore practised?

It can be so removed. And this may be effected by really doing that which the operators by the apparatus major only professed to accomplish, namely, by dilating the neck of the bladder and contiguous part of the urethra. But this must be done in a very different manner from that which they adopted. Instead of the dilatation being quick, and consequently painful, it must be slow and unattended with pain; and to accomplish this a very different means must be employed from any which they employed. Such dilatation cannot be made unless the pressure by which it is effected be perfectly equal, or applied to every part of the surface; unless it be of a continued nature, as from elasticity, and unless it be in the power of the surgeon or the patient himself to increase or diminish it immediately, and without irritation, according as the feelings of the patient or other circumstances may require. This combination of desirable ends cannot be attained otherwise than by a dilator constructed on the principle of fluid pressure.

The operators by the Marian method were not unacquainted with the fluid dilator. They, at least, were aware of the report by Prosper Alpinus, that some means of the kind had been used in Egypt ; but, not understanding the principle of fluid pressure, they appear to have regarded the report as fabulous. Colot, the last celebrated operator by the apparatus major, in alluding to this reported Egyptian practice, says " there is no inflation, however painful it may be, capable of dilating the neck of the bladder sufficiently for the extraction of stone."* The

* “' Il n'y a point de vent, quelque violent qu'il soit, qui en puisse dilater l'orifice pour en faire sortir la pierre." It is surprising 
fact that a similar objection was at first made, even by surgeons of some note, to fluid pressure, as a means of dilating strictures, in the urethra and other canals, and this, too, long after the invention of Bramah's hydraulic press, will prevent any surprise at the incredulity of the Marian operators.

It was in the year 1819, while engaged with the subject of applying fluid pressure to the removal of strictures in the different canals of the body, and after ascertaining its vast superiority for this purpose to bougies and other ordinary measures, that the idea occurred to me of gradually opening the male urethra by the same expedient for the extraction of stone. I had, a short while before, witnessed the tortures of a friend who was labouring under stone, for which he had been unsuccessfully cut by an eminent provincial

that they who delight in illustrations of the adage that " there is nothing new under the sun," should not have fixed upon this Egyptian plan as a notable one in connection with the recent operation for stone. It would have been much more to their purpose than the suggestion of $\mathrm{Mr}$.J. Douglas, in one of the early volumes of the "Philosophical Transactions ;" for, though he recommends slow dilatation, he does not say how it can be effected, the means proposed by him being as inadequate for the purpose as the lately invented flying machine is to accomplish another very desirable object. There is a mighty distance between stating what is desirable and pointing out how it is to be accomplished. To take an example from the subject before us : it were much to be wished that the urinary calculus could be dissolved instead of being extracted by operation, but where to find the solvent is the difficulty.

The amusing circumstance connected with the subject is, that the erudition which has brought to light so many resemblances between former and present plans of treating urinary calculus, had its source in the endeavour of the supposed French originator of lithotrity to prove that he was not indebted to a modern and living writer for his instruments, but to "l'ancienne chirurgerie,"- the writings of the ancients. In evidence of this I have elsewhere brought together some curious facts, and can only venture (limited, as I am, in space) to notice here, in illustra= tion of the carelessness or inaccuracy with which the French treat of such matters, that in the "Dictionaire de Medicine et Chirurgerie," and the article "Cystotomie," bearing the respectable signature of Baron Dupuytren, a suggestion of $M$. Guerin, to remove stone by slow dilatation, is mentioned as having been made in 1816 (four years before my publication on the subject), and as having been attended with numerous instances of success, although it was really only made in 1826 ! surgeon, and I had sent him a copy of my recently-published work on the various ap. plications of fluid dilatation. He came to London, and soon afterwards, as has been related elsewhere, one of the suggestions in my work was acted upon under the liberal sanction of Sir Astley Cooper, who had the principal charge of the case; and a stone of considerable magnitude was extracted by dilatation, without his having endured pain, and without being followed by a longer confinement to the house than nine days.

In some remarks appended to the published account of this case the principle of the operation was stated to be to dilate slowly, and without causing pain or irrita. tion to such extent as can be safely done; and then, if necessary for easy extraction, to break the stone or otherwise reduce its size.

I have traced, in another publication, the effects which the announcement of this extraordinary operation had in France (in this country it was not appreciated by those who had the opportunity of practically continuing the investigation), and only advert to the subject here for the purpose of remarking that, although M. Civiale in his first publcation upon the removal of stone without cutting, recommended, as the first stage of the proceeding, the distention of the urethra by a fluid dilator, he soon dropped this first stage, and with the other French surgens who simultaneously applied themselves to the subject, confined his attention to the second stage, or the mechanical diminution of the stone.

Whether this abandonment of dilatation arose from a misunderstanding of the nature of the instrument for fluid pressure, or from other reasons of a less reputable character, it is needless to inquire; but it is certain that by the rejection of the first stage the improvement was much deteriorated, and rendered only applicable to a minority of the cases of stone which occur.*

* M. Dubois, in 1827, recommended performing lithotrity by inserting the lithontriptor through such a small opening ("boutonniere") made in the perineum, as I had proposed, for dilatation and lithotrity combined; and the suggestion is favourably received by the writers of the article "Lithotritie," in the "Dictionaire de Me. dicine et Chirurgerie," vol. xi. But M. Civiale was not likely, upon reflection (for at first he appears, by a statement in this article, to have commended it), to approve of a plan so well calculated to bring back the mind of the inquirer to the original aud foreign operation. $\mathrm{He}$ accordingly assails it in one of his numerous publications, endeavouring absurdly to make it appear that any employment of the knife seriously alters the character of the operation, and omitting to state that though lithotrity has been termed a bloodless operation, the knife has 
Having expressed the opinion that the discovery of an adequate means for fulfilling the indication of slow dilatation was the great desideratum, and that this can only be done by an instrument constructed on the principle of fluid pressure, I proceed to notice the successive improvements this in. strument has undergone, with a view of fixing the reader's attention on particulars in its construction which $I$ conceive are essential to its perfect use.

Fluid distention was, as the Arabians employed it, in its first and rudest condition. We are told by Alpinus that an extensible cartilaginous tube having been passed along the urethra into the bladder was inflated by the surgeon's breath, so as to open a passage for the removal of the calculus by suction. A tube, consisting 'of a piece of gut (and such probably was its nature) would soon yield where there was least resistance, and could not exert sufficient power.

The frist and most obvious improvement consisted in giving the distensible tube another coat of firm and unyielding texture. A silk tube enclosed the piece of gut, prepared by stripping off its mucous and muscular coats, and this tube may be made either by sewing together the edges of a bit of rubber, or (as I have lately ascertained) by weaving it of the required dimensions. $A$ silk tube of this description may be rendered sufficiently impervious as well as smooth by varnish, instead of a lining and covering of gut; and if covered with a little adhesive matter and rolled upon itself (as a sheet of paper is rolled) it has the size and resistance of the smallest bougie, and may be passed through the narrowest strictures. This modification is the last improvement the fluid dilator has undergone, as respects its strength and bulk, but in the extraction of stone it is not necessary that it should be smaller in its empty and compressed state than a large-sized catheter or bongie. Both ends of the distensible tube must, for this use of it, be tied upon a narrow silver tube or catheter, in order that there may be no impediment to the evacuation of the urine, the distending liquid being injected by a syringe through a separate tube soldered to the catheter.

been frequently used in it to open the orifice of the urethra.

If lithotrity, without previous dilatation, were to be continued in practice, it would probably be more safely performed in this way than when the whole urethra is subjected to injury from instruments or fragments of stone, and the operator is embarrassed in the use of his apparatus by the great length of the passage. By the pressare of a cushion surrounding the lithontriptor against the perineum, the necessary steadiness would be afforded and the injected liquid (mercury and water) retained.
Notwithstanding the care taken in the construction of the instrument, and particularly that the gut should be well sup. ported by its silk tunic, much annoyance and discouragement were often experienced by the escape of the injected fluid, under considerable pressure, from the distensible tube or the different joinings; and when used for the extraction of stone, much irregularity of an injurious tendency was likely to result from this. After many years the idea occurred to me of substituting thick mucilage for air or water, and I found that this viscid substance will hardly escape through openings which would render the instrument useless were the other liquids employed.

The last improvement was a means of easily regulating the pressure. Injecting more fluid at intervals, and retaining it or allowing it to escape by closing or opening a stop-cock, is an imperfect mode of accomplishing this. By using a syringe, which has a piston-rod made in the form of a screw, the pressure can be regulated with the greatest ease by the surgeon, or in some cases by the patient himself. In cases of stricture of the rectum such a syringe may be conveniently attached to the fluid dilator by a long flexible impervious silk or caoutchouc tube, which prevents any motion of the syringe being communicated to the dilator, indicates by its hardness the degree of distention, and allows the syringe to be kept in a vertical position, in order that the air in it (which is necessary to keep up the elastic pressure) may be prevented escaping from the joinings ol tubes. In dilating for stone the syringe should be of large size, or a vessel, serving as a reservoir of air and $\mathbf{m u}$ cilage, may be attached by the medium of the flexible tube to the dilator.

(To be concluded.)

\section{EMETICS.}

THE use of these medicines in stimulating into action the vis medicatrix nature, has been amply proved in two cases occurring lately at the Hôpital de la Pitie, Paris. One was that of a man who had sustained severe injury on the head, followed by incipient infammation, which several bleedings and the local application of ice employed throughout two days failed to subdue. A copions emetic was administered, and in less than twenty-four hours the symptoms had dissipated. The other case was that of a woman recently operated on for cancer, and afterwards the subject of a bronchitis so severe as to threaten a fatal termination. Bleeding was interdicted by the weak state of the patient, and a large blister on the chest proved useless. An active emetic of tartarised antimony, however, brought in its train a speedy cure.-Gazette des Hôpitaux, June. 